\title{
Implementação de uma metodologia laboratorial para reprodução de uma turbina eólica com o LabVIEW
}

\author{
Implementation of a laboratory methodology for reproducing a wind turbine with LabVIEW \\ Implementación de una metodología de laboratorio para la reproducción de una turbina eólica con
}

LabVIEW

Recebido: 16/12/2021 | Revisado: 21/12/2021 | Aceito: 24/12/2021 | Publicado: 05/01/2022

Leonardo Corrêa Caixeta

ORCID: https://orcid.org/0000-0001-5664-4102

Centro Universitário de Patos de Minas, Brasil

E-mail: leoccaixeta@gmail.com

Victor Henrique da Cunha Faria

ORCID: https://orcid.org/0000-0003-0063-6319

Universidade Federal de Uberlândia, Brasi

E-mail: victorhcf@ufu.br

Gaspar Eugênio Oliveira Ramos

ORCID: https://orcid.org/0000-0002-0612-1343

Centro Universitário de Patos de Minas, Brasil

E-mail: gasparramos@unipam.edu.br

\begin{abstract}
Resumo
Visto a constante expansão da energia eólica no cenário energético mundial é necessário que se apresente métodos capazes de reproduzir os efeitos eletromecânicos dessa fonte, de modo a aprimorar o conhecimento e os avanços tecnológicos. O intuito deste trabalho foi implementar e avaliar o desempenho da metodologia laboratorial para reprodução de turbinas eólicas, por meio de máquinas elétricas controladas via software. Para tal fim, desenvolveu-se em LabVIEW uma plataforma destinada a modelagem e controle do sistema eólico, aplicando um motor de corrente contínua para reprodução da potência extraída pela turbina, sendo acoplado ao eixo de um gerador síncrono alimentando a carga consumidora de energia. O estudo de desempenho baseou-se na simulação de três casos buscando analisar parâmetros de operação constante, incidência de turbulências do vento e atuação do sistema de controle da turbina. Os resultados encontrados foram satisfatórios perante o modelo didático em escala reduzida, que possibilitou verificar os efeitos eletromecânicos advindos das condições impostas. Constatou-se que a operação da turbina se altera de forma expressiva para pequenas mudanças do vento, influenciando na extração de potência mecânica e nas tensões geradas pelo sistema.
\end{abstract}

Palavras-chave: Aerogeradores; Energia eólica; LabVIEW; Máquinas elétricas.

\begin{abstract}
Seen the constant expansion of wind energy in the global energy scenario, it is necessary to present methods capable of reproducing the electromechanical effects of this source, in order to improve knowledge and technological advances. The aim of this work was to implement and evaluate the performance of the laboratory methodology for reproduction of wind turbines, using electrical machines controlled via software. For that, a platform was developed in LabVIEW for modeling and controlling the wind system, employing a direct current motor to reproduce the power extracted by the turbine, being coupled to the axis of a synchronous generator feeding a energy consuming load. The system performance study was based on the simulation of three cases, seeking to analyze parameters of constant operation, incidence of wind turbulence and behavior of the turbine control system. The results archived were gratifying by the didactic model on a reduced scale, which made it possible to verify the electromechanical effects arising from the imposed conditions. It was found that the operation of the turbine changes significantly for small wind alterations, influencing the extraction of mechanical power and the voltages generated by the system.
\end{abstract}

Keywords: Aerogenerator; Wind energy; LabVIEW; Electrical machines.

\section{Resumen}

Dada la constante expansión de la energía eólica en el escenario energético global, es necesario presentar métodos capaces de reproducir los efectos electromecánicos de esta fuente, con el fin de mejorar el conocimiento y los avances tecnológicos. El objetivo de este trabajo fue implementar y evaluar el desempeño de la metodología de laboratorio para la reproducción de aerogeneradores, utilizando máquinas eléctricas controladas vía software. Para ello, desarrollar en LabVIEW, una plataforma para modelar y controlar el sistema eólico, aplicando un motor de corriente continua para reproducir la potencia extraída por la turbina, siendo acoplado al eje de un generador síncrono que alimenta la carga 
consumidora de energía. El estudio de desempeño se basó en la simulación de tres casos analizando parámetros de operación constante, impacto de turbulencias eólicas y desempeño del sistema de control de la turbina. Los resultados encontrados fueron satisfactorios ante el modelo didáctico a escala reducida, lo que permitió verificar los efectos electromecánicos derivados de las condiciones impuestas. Parece que el funcionamiento de una turbina cambia significativamente por pequeños cambios en el viento, lo que influye en la extracción de energía mecánica y los voltajes generados por el sistema.

Palabras clave: Aerogenerador; Energía eólica; LabVIEW; Máquinas eléctricas

\section{Introdução}

A demanda por energia elétrica vem aumentando gradualmente com o passar dos anos, assim como a responsabilidade das grandes nações mundiais em buscar uma geração baseada em fontes renováveis para diminuir o impacto ambiental. No âmbito das energias renováveis, a energia eólica segue se consolidando como uma fonte promissora e em crescente exploração a nível mundial, sendo a mais notável entre as renováveis (Parreiras \& Silva, 2012).

A fonte primária para a geração eólica é o vento, definido como o movimento das massas de ar no globo. As forças mecânicas presentes nessas massas de ar integram uma imensa fonte de energia natural, que é transformada em energia elétrica por aerogeradores. Há de se ressaltar que o comportamento físico desta fonte primária quanto a velocidade, direção e intensidade não são constantes, devido ao vento sofrer com as contínuas mudanças de temperatura e pressão no globo (Alvarenga, 2012).

O atual cenário de desenvolvimento e expansão da energia eólica direciona para um futuro promissor desta fonte, que conforme as características citadas, implicam na necessidade de pesquisas e métodos para testes de desempenho e comportamento. Testes esses, que visem aproveitar o máximo potencial possível e o aperfeiçoamento tecnológico, assim como estudar os fenômenos elétricos e mecânicos provindos dessa geração.

Isto posto, uma solução para realização de testes é o túnel de vento, responsável por conceder velocidades de vento até $20 \mathrm{~m} / \mathrm{s}$ utilizando motores controlados para reproduzir as condições reais do fluido. Porém, a construção de um túnel para estudos acarreta alto investimento financeiro e complexidade em sua montagem. Em contraponto a isso, surgiram os modelos computacionais por meio de estruturas laboratoriais que envolvem o controle de máquinas elétricas através de softwares, tais estratégias podem reproduzir o comportamento real, ou em modelo simplificado, dos resultados da geração eólica, sendo uma alternativa economicamente mais viável (Xavier, 2012).

Visto a importância do desenvolvimento das energias renováveis no atual cenário, o futuro da geração de energia eólica proporcionará oportunidades de pesquisas para a sua evolução e expansão. Os métodos de análise computacional aplicados a estruturas laboratoriais, demonstram ser linhas de pesquisas bastante atrativas, já que, além de economicamente mais viáveis, possibilitam a realização de testes na geração eólica sem que haja um aerogerador, ou necessidade da construção de estruturas extremamente complexas.

Por conseguinte, visando aplicar um método que supra as adversidades nos estudos desta fonte de energia em ampla expansão no cenário energético, o presente trabalho tem por objetivo a reprodução de uma unidade geradora de energia eólica por meio da metodologia laboratorial, sem a construção de túneis de vento. Aplicando as técnicas de modelagem do vento e de um aerogerador através do software LabVIEW, controlando um motor de corrente contínua para reproduzir os efeitos e as características da geração eólica. Isto permitirá a análise do comportamento eletromecânico dessa geração frente às diferentes condições de vento encontradas, verificando o desempenho do método proposto.

\section{Materiais e Métodos}

O projeto exposto visa a reprodução de uma estrutura real de geração eólica em laboratório, aplicando técnicas de modelagens no software LabVIEW e o controle de uma máquina de corrente contínua (CC). Para tal, a metodologia executada 
na construção e na coleta de resultados, seguiu um direcionamento bibliográfico, caracterizada como uma pesquisa de campo exploratória com abordagem qualitativa.

A execução do modelo proposto depende do conhecimento do funcionamento e comportamento de um aerogerador, assim como as características do vento e da energia eólica. Dado que a modelagem desses aspectos se dará por métodos matemáticos a fim de controlar o motor de corrente contínua para reprodução do sistema. Para melhor entendimento será apresentado os conceitos adotados neste tópico.

\subsection{Fundamentos da Energia Eólica}

A conversão da energia do vento em eletricidade é feita por turbinas eólicas que transferem o movimento mecânico rotacional a um gerador elétrico. As turbinas diferem em sua aerodinâmica quanto ao eixo de rotação, podendo ser do tipo horizontal ou vertical (Mendes, 2009). As turbinas horizontais são mais usuais em grande maioria nos parques eólicos, pois possuem melhor rendimento com estrutura física mais simples e consistente. Turbinas constituídas de três pás são as mais comuns, pois a simetria nesta configuração anula os esforços mecânicos periódicos (Xavier, 2012). Á vista disso, a metodologia é direcionada as turbinas de eixo horizontal.

A energia cinética presente no vento sofrerá alterações em sua magnitude, já que as contínuas mudanças de temperatura e pressão alteram a velocidade, intensidade e direção do fluido. A potência do vento é o fluxo de energia cinética, indicando o montante da energia por tempo em uma determinada área (Kalmikov, 2017). Dado isso uma expressão bastante difundida que relaciona a potência mecânica extraída pela turbina com a potência do vento é apresentado abaixo (1), sendo $\mathrm{P}_{\text {mec }}$ a potência mecânica na turbina (Slootweg et al., 2003).

$$
P_{m e c}=\frac{C p \cdot \rho \cdot A_{p a ́ s} \cdot v^{3}}{2}
$$

Onde:

$\rho=$ massa específica do ar $\left(1,225 \mathrm{~kg} / \mathrm{m}^{3}\right.$ na temperatura de $25^{\circ} \mathrm{C}$ e $\left.1 \mathrm{~atm}.\right)$;

$A_{\text {pás }}=$ área varrida pelas pás das turbinas $\left(\mathrm{m}^{2}\right)$;

$v=$ velocidade do vento $(\mathrm{m} / \mathrm{s})$.

O coeficiente de potência $C p$ indica o rendimento da turbina eólica, podendo ser descrito em função de duas variáveis, a primeira é expressa pelo coeficiente adimensional $\lambda$ "razão de velocidade de pá" (3), e é dado pela razão da velocidade na ponta da pá e a do vento. A segunda, é o ângulo de passo das pás da turbina representado por $\beta$, referente a rotação das pás em torno do seu eixo longitudinal (Gao \& Luo, 2009). As características aerodinâmicas da turbina são introduzidas no cálculo do $C p$ através dos coeficientes $c_{1}$ a $c_{9}(2)$ (Alvarenga, 2012).

$$
C p(\lambda, \beta)=c_{1} \cdot\left(\frac{c_{2}}{\lambda_{1}}-c_{3} \cdot \beta-c_{4} \cdot \beta^{c_{5}}-c_{6}\right) \cdot e^{-\frac{c_{7}}{\lambda_{1}}}
$$

Sendo: 


$$
\lambda_{1}=\frac{1}{\left(\frac{1}{\lambda+c_{8} \cdot \beta}-\frac{c_{9}}{\beta^{3}+1}\right)} \quad \lambda=\frac{\omega_{\text {turbina }} \cdot R}{v}
$$

Onde:

$\omega_{\text {turbina }}=$ velocidade angular da turbina $[\mathrm{rad} / \mathrm{s}] ;$

$R=$ raio da turbina eólica;

$\mathrm{v}=$ velocidade do vento.

\subsection{Modelagem da Fonte Primária}

As características aleatórias do vento influenciam diretamente na potência disponível para a geração de energia, logo torna-se importante conhecer os tipos de variações presente neste fluido. A variação dos fenômenos fundamentadores do vento provoca mudanças na velocidade do vento ao longo do dia, contendo alternâncias de curta duração como flutuações (turbulências) e rajadas de vento. Estas variações sucedem em intervalos de minutos a até décimos de segundos, causando forças cíclicas nos componentes dos aerogeradores (Fadigas, 2011). A Figura 1 retrata as variações intrínsecas de velocidade do vento em uma curta duração.

Figura 1: Variações típicas da velocidade do vento.

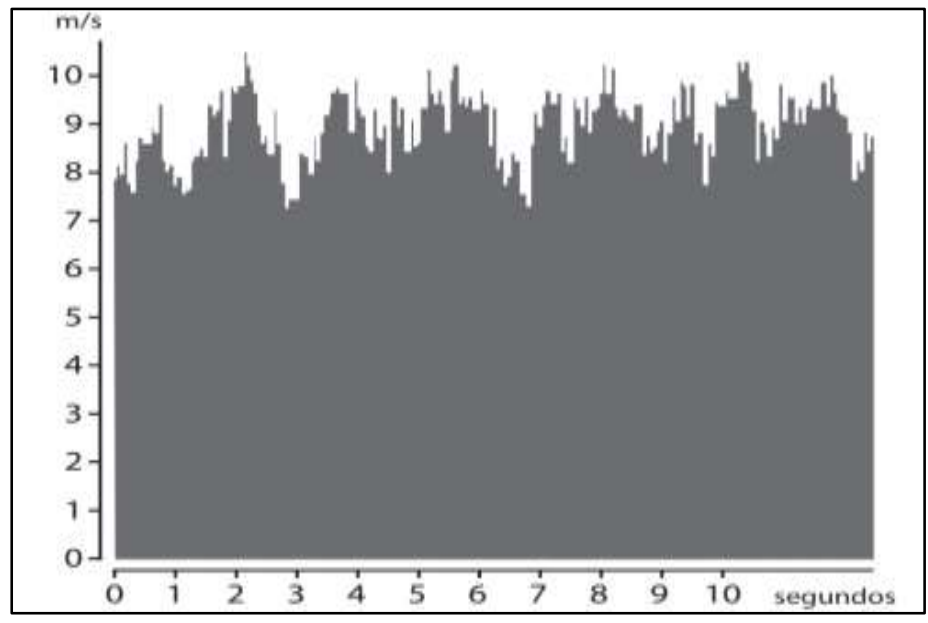

Fonte: Fadigas (2011).

Para representar a velocidade da fonte primária à energia eólica é necessário fazer uso de uma modelagem que reproduza os aspectos ilustrados na Figura 1 de maneira fiel ao comportamento do vento (Bonelli, 2010). Para tal, será adotado o modelo matemático (4) que contempla a velocidade do vento composta por quatro componentes, sendo elas: vento constante, rajada, rampa e ruído (Silva, 2006).

$$
\text { Vvento = Vmédia }+ \text { Vrajada }+ \text { Vrampa }+ \text { Vruído }
$$

A velocidade média (Vmédia) é a componente principal, estando sempre presente na velocidade do vento, é representada por um valor base constante. Já a segunda componente (Vrajada) expressa a variação resultante da velocidade em forma de rajada, através de uma função cossenoidal. A componente rampa (Vrampa), propriamente já indica, descreve uma variação do vento em formato de uma rampa linear (Xavier, 2012). A última componente é expressa como ruído (Vruído), indica a parte 
aleatória do sinal que também está sempre presente no fluido. Para reprodução deste efeito, utiliza-se de uma rotina lógica computacional para gerar de forma aleatória as amplitudes da densidade espectral presente (Carvalho, 2006).

\subsection{Máquina de Corrente Contínua}

Para reprodução do comportamento de uma turbina eólica em laboratório, o método mais conveniente é empregar o controle de um motor elétrico conectado diretamente ao eixo de um gerador. Habitualmente, a máquina de corrente contínua é a melhor opção na emulação de uma turbina, já que pode ser controlada pela corrente na armadura que associa-se diretamente ao torque produzido (Karzov \& Milenov, 2015).

Os motores CC propiciam operações com ampla faixa de velocidade e com saída de precisão em seu controle, seja em operações dinâmicas ou em regimes permanentes, devido a suas características de tensão por corrente ou velocidade por conjugado (torque) (Umans, 2014).

O presente trabalho emprega o motor CC em derivação, conhecido como paralelo ou shunt. Para este tipo de ligação, a armadura e o enrolamento de campo são conectados em paralelo com a fonte de excitação, desta forma, a rotação e o torque serão consequências da interação entre os dois campos magnéticos gerados na máquina (Nascimento Junior, 2013).

As características desta máquina englobam sua velocidade e o conjugado em seu eixo. Analisando a potência convertida (9) de um motor CC obtém-se seu funcionamento para qualquer valor de carga, sendo exibido abaixo. Onde $\mathrm{E}_{\mathrm{A}}$ simboliza a tensão induzida na armadura, $\mathrm{I}_{\mathrm{A}}$ a corrente na armadura, $\tau$ o conjugado induzido e $\mathrm{w}_{\mathrm{m}}$ a rotação do motor (Chapman, 2013).

$$
P_{\text {conv }}=E_{A} \cdot I_{A}=\tau \cdot w_{m}
$$

Desta forma, para o cálculo da potência no eixo será realizada através da medição da tensão induzida na armadura e da corrente na armadura.

\subsection{Estrutura Física do Sistema}

O sistema eólico funcionará de forma isolada da rede, alimentando diretamente uma carga responsável por consumir a energia produzida. Para a reprodução da turbina é realizado a modelagem do vento incidente e dos parâmetros aerodinâmicos e elétricos do aerogerador através do LabVIEW, desta forma será fornecido a potência mecânica ao qual o motor CC shunt representará a potência extraída pela turbina. A arquitetura de funcionamento do sistema é retratada na Figura 2, destacando o conjunto responsável por reproduzir o comportamento da turbina eólica. 
Figura 2: Arquitetura laboratorial do sistema eólico isolado.

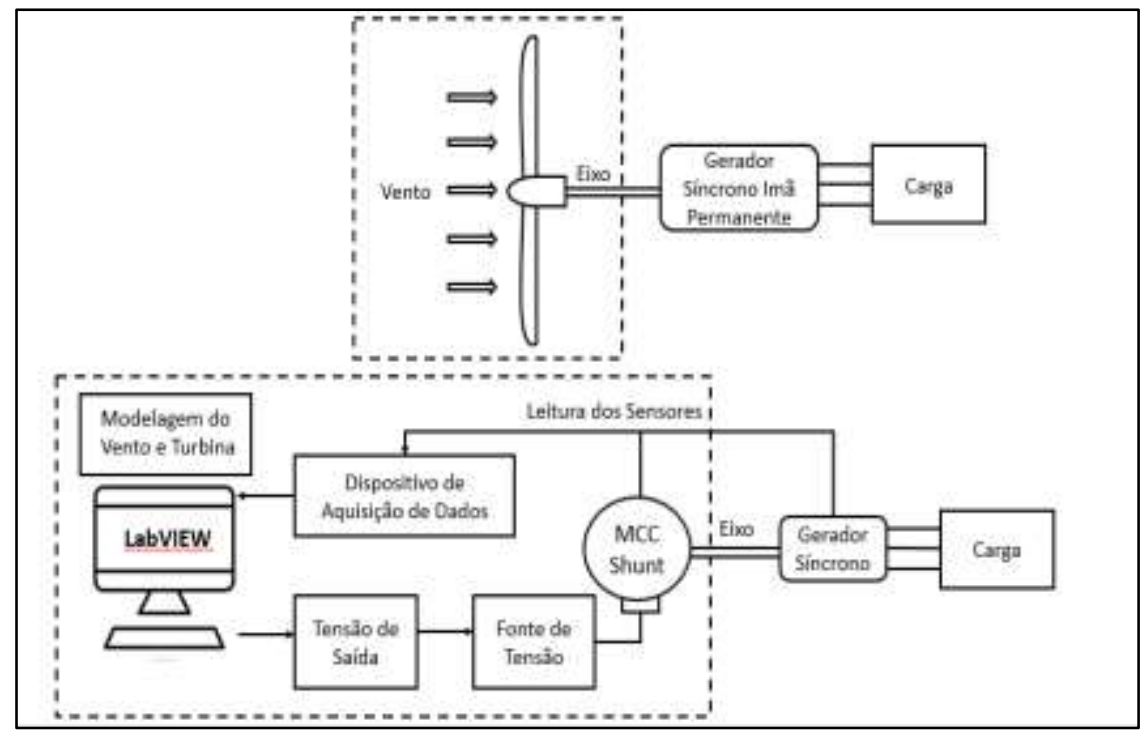

Fonte: Autores (2021).

Nota-se também na Figura 2, que é acoplado ao motor CC um gerador síncrono que irá gerar a energia direcionada a carga consumidora. Destaca-se que o LabVIEW também será responsável pela aquisição das leituras dos sensores, além do controle da fonte de tensão que acionará o motor. Por fim, a estrutura laboratorial montada no UNIPAM é apresentada na Figura 3, logo após é indicado maiores detalhes sobre os componentes. Salienta-se que todos os itens necessários foram disponibilizados pelo Laboratório de Conversão de Energia.

Figura 3: Estrutura física montada.

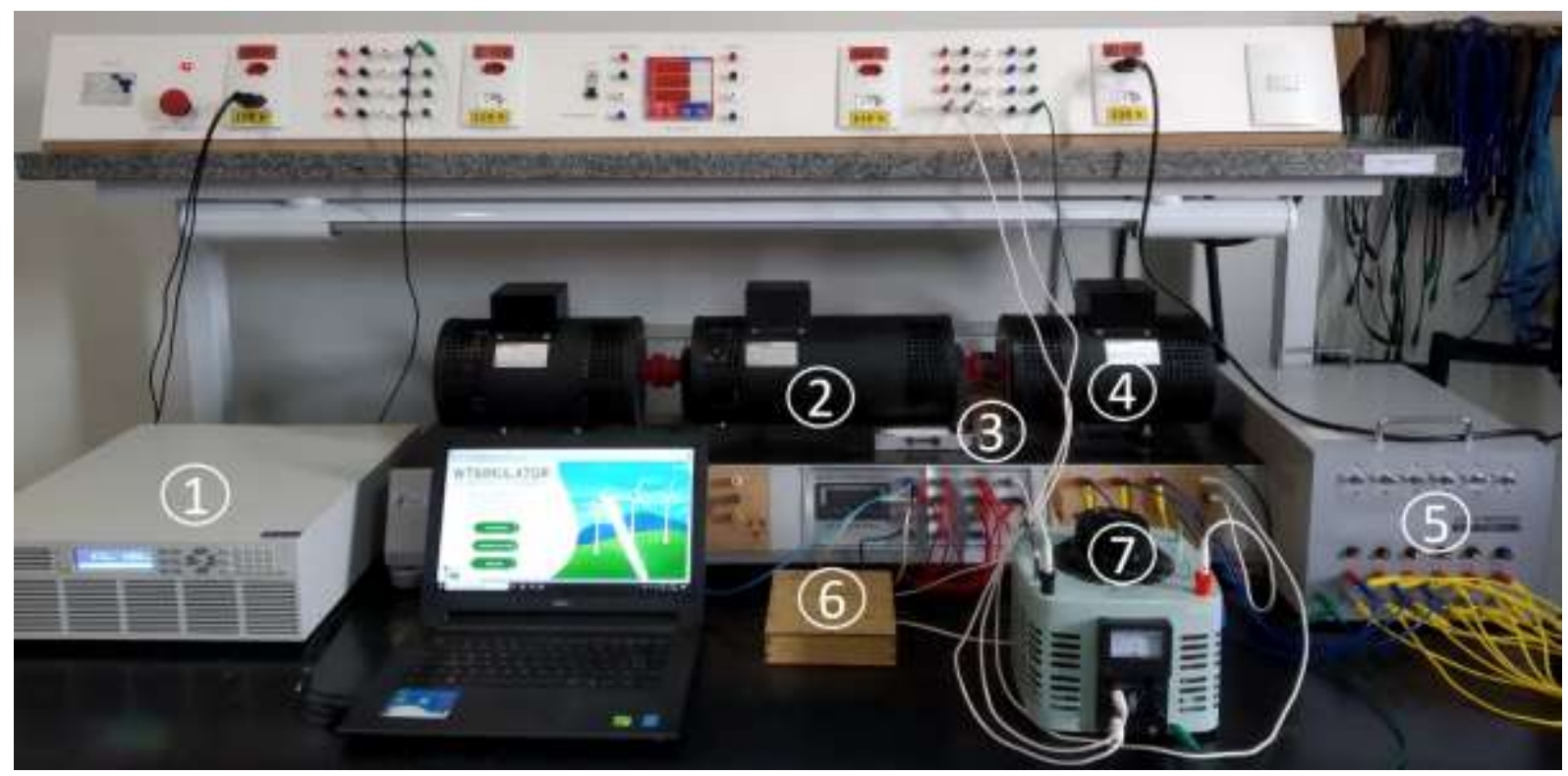

Fonte: Autores (2021).

Dado a estrutura laboratorial na Figura 3, é apresentado a fonte de tensão (1) Keysight AC 6803A responsável por alimentar o motor CC. A fonte possuí potência máxima DC de $1600 \mathrm{~W}$, com tensão de saída de 190 Vcc. O motor CC (2) conectado em shunt possui $1 \mathrm{cv}$ de potência $(735,499 \mathrm{~W})$, com rotação nominal de $1800 \mathrm{rpm}$, e tensão na armadura de $160 \mathrm{Vcc}$. Para a medição da rotação do sistema, foi projetado um encoder óptico (3) que se encontra no eixo do motor, entregando um sinal oscilatório ao software onde será calculado as rotações por minuto. 
Ainda na Figura 3 observa-se um gerador trifásico síncrono (4) ligado em delta, onde para esta aplicação, operará igualmente a um gerador de imã permanente através de uma excitação fixa em seu enrolamento de campo. Possuí potência de $0,75 \mathrm{cv}(551,62 \mathrm{~W})$, com tensão de linha $220 \mathrm{~V}$ e um rendimento de aproximadamente 74,6\%. Junto ao gerador pode-se notar a ligação de uma carga resistiva (5) composta por 6 resistências conectadas em estrela em paralelo, formando uma carga trifásica equilibrada consumindo do gerador na tensão nominal uma potência de 423 W. A fim de excitar o gerador síncrono, é usado um variac monofásico (7) onde irá fornecer uma tensão fixa de campo.

A medição dos sinais da simulação é realizada pelo sistema apresentado em (6). Foi utilizado o dispositivo de aquisição de dados (DAQ) NI USB 6002, responsável pela conversão analógica/digital e o condicionamento dos sinais para o software. Possui um conversor de 16 bits com até 8 canais de entradas analógicas, oferecendo medições entre $-10 \mathrm{~V}$ a $+10 \mathrm{~V}$. Apresenta também saída digital de $5 \mathrm{~V}$.

O sistema de medição contém 5 canais, apresentado as medições do encoder (rotação), corrente e tensão na armadura do motor CC, tensão e corrente no gerador síncrono. Para a leitura das tensões do motor e do gerador, é aplicado um divisor de tensão já que o DAQ realiza leituras de no máximo $\pm 10 \mathrm{~V}$. Para leitura da corrente de armadura foi adotado o sensor de efeito hall ACS 712, sendo este sensor capaz de converter o sinal de corrente da armadura em um valor de tensão, apresentando uma relação de aproximadamente $66 \mathrm{mV} / \mathrm{A}$ com offset de tensão de 2,5 V. No monitoramento da corrente que percorre a armadura do gerador para a carga elétrica, aplicou-se um transformador de corrente (TC) SCT013 100A:50mA. Ressalta-se que todas as medições foram dimensionadas para respeitar os limites do DAQ.

\section{Resultados e Discussão}

Primeiramente será apresentado o modelo eólico de referência para a realização das simulações. Conforme a metodologia proposta, é necessário que se defina um aerogerador comercial que apresente as características aerodinâmicas para a sua reprodução, sendo expressado no Quadro 1 os atributos da turbina adotada.

Quadro 1: Parâmetros do sistema eólico de referência.

\begin{tabular}{|c|c|c|c|}
\hline \multicolumn{4}{|c|}{ Características da Turbina Eólica } \\
\hline Tipo & Raio (m) & № de Pás & Controle \\
\hline Horizontal & 21 & 3 & Pitch \\
\hline Velocidade Nominal & Cut-in & Cut-out \\
\hline \multicolumn{3}{|c|}{ Coeficientes Aerodinâmicos } \\
\hline \multicolumn{3}{|c|}{ C4 $4=0$} & $\mathrm{C} 7=12,5$ \\
\hline C1 120,22 & $\mathrm{C} 5=1$ & $\mathrm{C} 8=0,08$ \\
\hline C2 $2=116$ & C6 $=5$ & $\mathrm{C} 9=0,035$ \\
\hline C3 $=0,4$ & \multicolumn{3}{c|}{ Potência Nominal } \\
\hline \multicolumn{3}{|c|}{ Características do Gerador Trifásico } \\
\hline Topologia do Gerador & $00 \mathrm{~kW}$ \\
\hline Síncrono à Imã Permanente & No de Polos & Tensão \\
\hline Rotação Nominal & 60 & $600 \mathrm{~V}$ \\
\hline 33,6 rpm &
\end{tabular}

Fonte: Adaptado de Alvarenga (2012).

Trata-se de uma turbina horizontal de três pás, sendo um gerador síncrono de $600 \mathrm{~kW}$ com rotor de imã permanente. Analisando sua condição de operação nominal (vento $=12 \mathrm{~m} / \mathrm{s}$, rotação $=33,6 \mathrm{rpm}$ ), determina-se por meio das equações apresentadas no tópico 2.1 que sua razão de velocidade de pá otimizada é 6,157 , resultando em um $C p$ da turbina em 
aproximadamente $43,75 \%$. Desprezando as perdas mecânicas da turbina, em regime nominal é fornecido ao eixo do sistema uma potência na ordem de 641,673 kW.

Nota-se que no Quadro 1, que a turbina detém do método de controle pitch. Devido aos aerogeradores serem expostos a situações de aleatoriedade do vento, onde rajadas ou aumento gradual de sua velocidade podem ocasionar com que os limites de torque e potência sejam ultrapassados, devendo adotar medidas de correção ou proteção prevenindo danos futuros ao sistema eólico (Neto, 2005). Portanto, este controle pitch atua na rotação das pás girando o seu eixo para diminuir o contato aerodinâmico com o vento, limitando a potência gerada nos valores ideias de funcionamento (Silva, 2014).

Dado a turbina de referência, será exibido na sequência a adequação física elaborada, os parâmetros definidos e o software desenvolvido. E por fim, a análise e exposição dos resultados gerados, considerando os efeitos eletromecânicos advindos dessa energia alternativa.

\subsection{Adequação da Turbina para Escala Laboratorial}

A fim de reproduzir a turbina em uma escala reduzida, é primordial determinar o método de controle do motor apresentado. Consequentemente, realizou-se um ensaio da máquina CC alterando sua alimentação e mensurando a potência mecânica de saída, visando determinar sua curva de funcionamento. Para tal ensaio, o motor forneceu potência ao gerador que possuía uma carga linear fixa em seus terminais. É apresentado na Figura 4 a curva correspondente de funcionamento.

Figura 4: Curva de potência mecânica por tensão de alimentação do motor CC shunt.

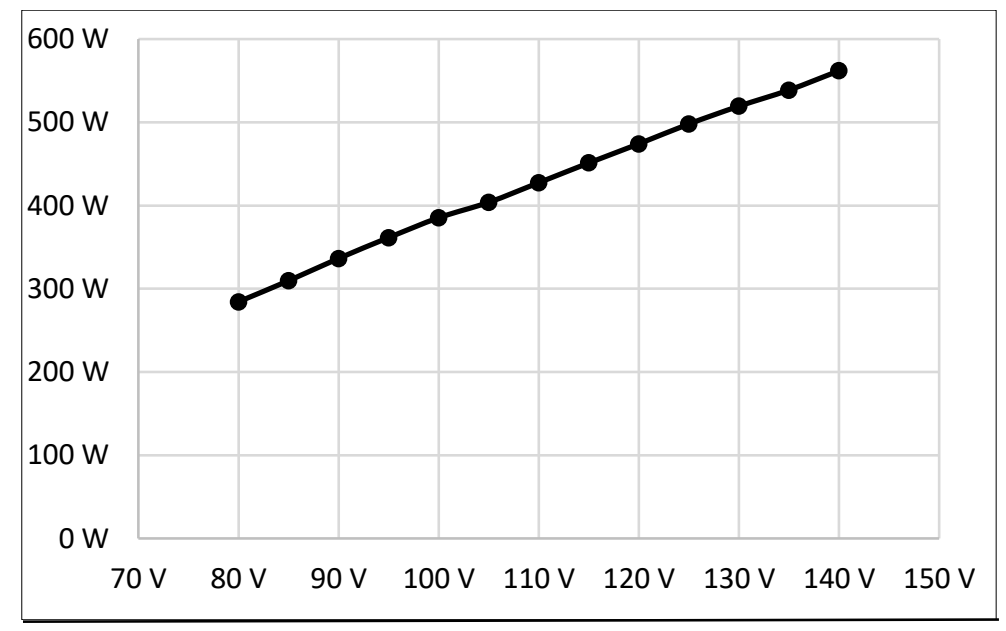

Fonte: Autores (2021).

Constata-se que o comportamento do motor apresenta uma relação extremamente linear, tendo uma ampla faixa de operação que permite um controle com precisão. Pode-se considerar que para todos os fins, uma equação linear da reta permite o controle deste motor sem muitas complicações, onde a fonte Keysight fornecerá a tensão necessária para a potência calculada no LabVIEW.

Com o controle de precisão do motor definido, é necessário definir a operação do conjunto de máquinas para a adaptação da turbina em uma escala reduzida. Como relatado anteriormente, a rotação nominal das máquinas é 1800 rpm e a tensão nominal do gerador $220 \mathrm{~V}$. Sabendo-se a potência nominal da carga resistiva de $423 \mathrm{~W}$, deve-se determinar qual a excitação necessária para que o gerador consiga performar seus valores nominais, no qual evidenciou uma tensão contínua e fixa (imã permanente) em seu campo de 104 Vcc. Para este ponto de operação, através do rendimento do gerador determina-se a potência mecânica nominal que o motor CC deve entregar, sendo aproximadamente $566 \mathrm{~W}$. 
Em conclusão, a operação nominal estabelecida corresponderá aos $600 \mathrm{~kW}$ produzidos pelo gerador eólico, quando sua turbina extraí 641,673 kW da potência do vento. A razão entre a escala de potência mecânica do arranjo didático e do aerogerador é de 1132,86, possibilitando assim durante as simulações encontrar os valores de potência reais do sistema eólico.

\subsection{Software Desenvolvido - WTSIMULATOR}

O software para aquisição e controle foi desenvolvido através do LabVIEW, sendo uma linguagem gráfica designada para instrumentação virtual. Possuí duas partes principais: painel frontal e diagrama de blocos, onde no painel frontal é feita a interface com o usuário fornecendo botões, gráficos, dentre outras ferramentas. O código fonte é realizado no diagrama de blocos usando estruturas de controle, funções lógicas, dentre outros. No diagrama de blocos é apresentado os terminais correspondentes aos objetos do painel frontal, dessa forma os dados fluem do usuário para o código, e vice-versa (Travis \& Kring, 2006).

O LabVIEW é excelente em aplicações para aquisição de dados, pois é compatível com diversos dispositivos de aquisição, permitindo comandá-los realizando leituras, gerando sinais e controlando sua aplicação, provendo uma plataforma universal para diversas propostas em áreas distintas (Witherspone, 2014). Por isto, é amplamente utilizado nas áreas acadêmicas e industriais, seja para pesquisas ou desenvolvimento, possibilitando a elaboração de programas de alta qualidade em curto prazo (Lin et al., 2011).

A interface com o usuário desenvolvida no painel frontal do LabVIEW apresentando diferentes telas, destinadas para cada mudança de evento durante o uso da aplicação. A Figura 5 contempla a tela inicial do software desenvolvido intitulado WTSIMULATOR.

Figura 5: Tela inicial do software desenvolvido.

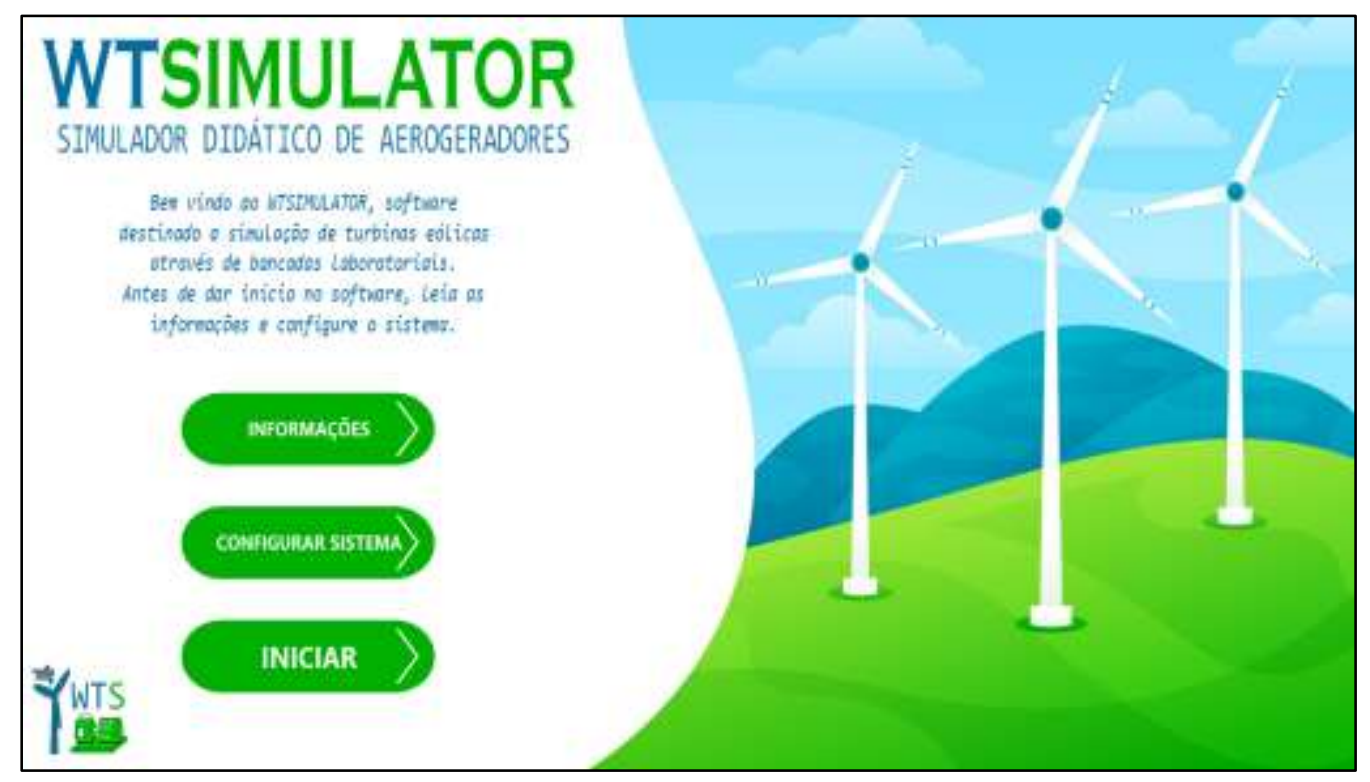

Fonte: Autores (2021).

Consoante com o ilustrado, o usuário terá acesso primeiramente as informações do programa e deverá configurar o sistema antes que inicie a simulação, durante os processos mais críticos são exibidas instruções de orientação das ações. Ao iniciar o simulador o usuário é direcionado ao longo dos processos para as telas subsequentes: "Partida do Motor", "Parâmetros do Vento" e "Painel de Simulação", essas telas direcionam as configurações da simulação. A Figura 6 retrata a tela responsável pela exibição e medição do sistema em tempo real. 
Figura 6: Tela de simulação do software desenvolvido.

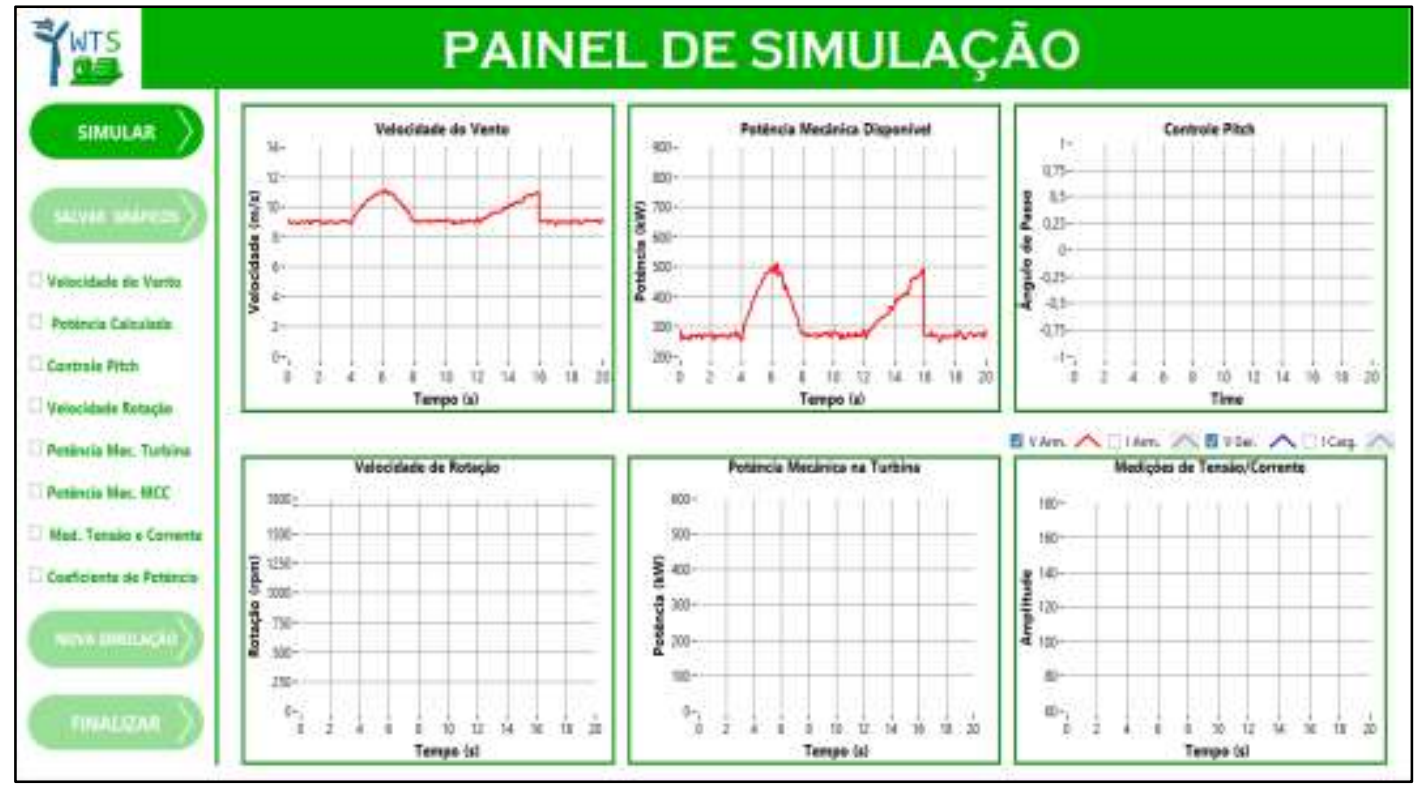

Fonte: Autores (2021).

O "Painel de Simulação" apresenta inicialmente ao usuário a velocidade do vento configurada e qual a potência mecânica teórica a turbina desempenharia. Ao pressionar o botão "Simular" é iniciado a simulação conforme os parâmetros definidos, bem como a medição em tempo real da velocidade de rotação, potência mecânica, tensões e correntes nas máquinas e operação do sistema de controle. Após a simulação, o usuário terá opção de exportar os gráficos obtidos para uma pasta a sua escolha, realizar uma nova simulação ou finalizar o processo.

O código referente da aplicação baseia-se na arquitetura de máquina de estados, onde apresenta diferentes estados em que a interação do usuário com o painel frontal determinará o fluxo da lógica. Como previamente dito, o usuário primeiramente configura os parâmetros da turbina e das máquinas elétricas. Em sequência é realizado todo o cálculo das propriedades nominais da turbina, dos limites de operação, a razão de potência do sistema, entre outros.

Após a partida do motor, estabelece os parâmetros de simulação como o tempo total e o vento base, definindo também as componentes que estarão presentes no vento (rajada e rampa), sua amplitude máxima, tempo inicial e tempo final para cada sinal adicionado. Com o vento incidente a simular, efetua-se o cálculo da potência mecânica teórica e verifica se a potência mecânica de saída excede a nominal. Em caso verdadeiro realiza o controle de passo das pás, de tal modo que limite o valor de saída respeitando as propriedades operacionais.

Por fim, tem se o cálculo da tensão de saída em cada ponto do sinal amostrado, reproduzindo a potência final extraída pela turbina com a relação da razão de potência equivalente do sistema laboratorial, permitindo a simulação e a medição.

\subsection{Resultados das Simulações}

Com finalidade de validar o método laboratorial proposto, o desenvolvimento do projeto baseou-se em três simulações de casos distintos do vento incidente, analisando para cada caso os fenômenos eletromecânicos impostos.

Para todos os fins, o funcionamento da turbina encontra-se próximo a sua faixa de vento nominal, sendo considerado que os mecanismos de controle atuaram nas velocidades abaixo da nominal otimizando a velocidade específica ("razão velocidade de pá”) em seu valor nominal, mantendo desta forma a máxima extração de potência sendo anteriormente denotado com um coeficiente de potência de $43,75 \%$. A escala de ruído do vento para a turbina em questão encontra-se de sinais aleatórios 
com amplitude máxima em 0,2 m/s do vento base, considerando o mesmo aspecto que trabalhos como Xavier (2012) e Carvalho (2006).

As componentes de vento adotadas para os casos são apresentadas no Quadro 2, ressaltando que a componente ruído está sempre presente no vento base. O tempo de simulação total foi definido em 20 segundos, contendo 10 amostras por segundo, desta forma o sistema de controle do motor e a medição atua a cada $100 \mathrm{~ms}$.

Quadro 2: Características do vento para os casos simulados.

\begin{tabular}{|c|c|c|c|c|c|c|c|}
\hline \multirow{2}{*}{ Caso } & Vento Base & \multicolumn{3}{|c|}{ Componente Rajada } & \multicolumn{3}{c|}{ Componente Rampa } \\
\cline { 2 - 8 } & Amplitude & Amplitude & Tempo Inicial & Tempo Final & Amplitude & Tempo Inicial & Tempo Final \\
\hline $\mathbf{1}$ & $9,5 \mathrm{~m} / \mathrm{s}$ & $0 \mathrm{~m} / \mathrm{s}$ & $0 \mathrm{~s}$ & $0 \mathrm{~s}$ & $0 \mathrm{~m} / \mathrm{s}$ & $0 \mathrm{~s}$ & $0 \mathrm{~s}$ \\
\hline $\mathbf{2}$ & $9,5 \mathrm{~m} / \mathrm{s}$ & $2 \mathrm{~m} / \mathrm{s}$ & $4 \mathrm{~s}$ & $8 \mathrm{~s}$ & $2 \mathrm{~m} / \mathrm{s}$ & $12 \mathrm{~s}$ & $16 \mathrm{~s}$ \\
\hline $\mathbf{3}$ & $9,5 \mathrm{~m} / \mathrm{s}$ & $3 \mathrm{~m} / \mathrm{s}$ & $4 \mathrm{~s}$ & $8 \mathrm{~s}$ & $3 \mathrm{~m} / \mathrm{s}$ & $12 \mathrm{~s}$ & $16 \mathrm{~s}$ \\
\hline
\end{tabular}

Fonte: Autores (2021).

No caso 1 é analisado a adaptação do sistema desenvolvido perante a um vento constante somente com a componente ruído, constituindo-se de um vento base de 9,5 m/s. O mesmo valor base será adotado para as demais situações. A fim de analisar o efeito das turbulências incidentes em uma turbina eólica, o segundo caso aplica as componentes rajada e vento assumindo valores máximos de 11,5 m/s, permanecendo abaixo da velocidade nominal da turbina. Para o último caso, a velocidade do vento chegará a 12,5 m/s ultrapassando desta forma o valor nominal da turbina, onde será analisado a atuação teórica do sistema de controle pitch que deverá limitar a potência extraída.

\subsubsection{Resultados do Caso 1}

A Figura 7 evidencia a rotação medida do arranjo laboratorial referente a simulação de um vento constante de $9,5 \mathrm{~m} / \mathrm{s}$ com a componente ruído.

Figura 7: Rotação do sistema laboratorial - Caso 1.

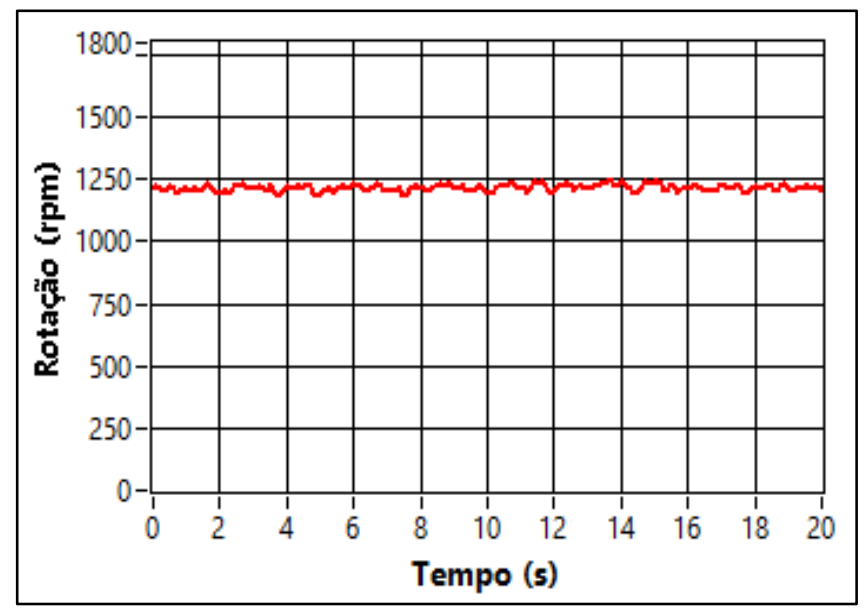

Fonte: Autores (2021).

O comportamento da velocidade mecânica do sistema se apresentou praticamente constante em torno de 1240 rpm, sofrendo pequenas oscilações na rotação devido ao ruído presente na velocidade do vento.

A fim de validar a atuação do sistema quanto a representação da potência real da turbina, é realizado no WTSIMULATOR o cálculo da potência mecânica teórica que a turbina desempenharia, sendo demonstrado na Figura 8 junto a 
potência medida no eixo. Ressalta-se que a potência medida se encontra na ordem de kW, aplicando a relação de adaptação do modelo laboratorial para o real.

Figura 8: (a) Potência mecânica teórica; (b) Potência mecânica extraída pela turbina.

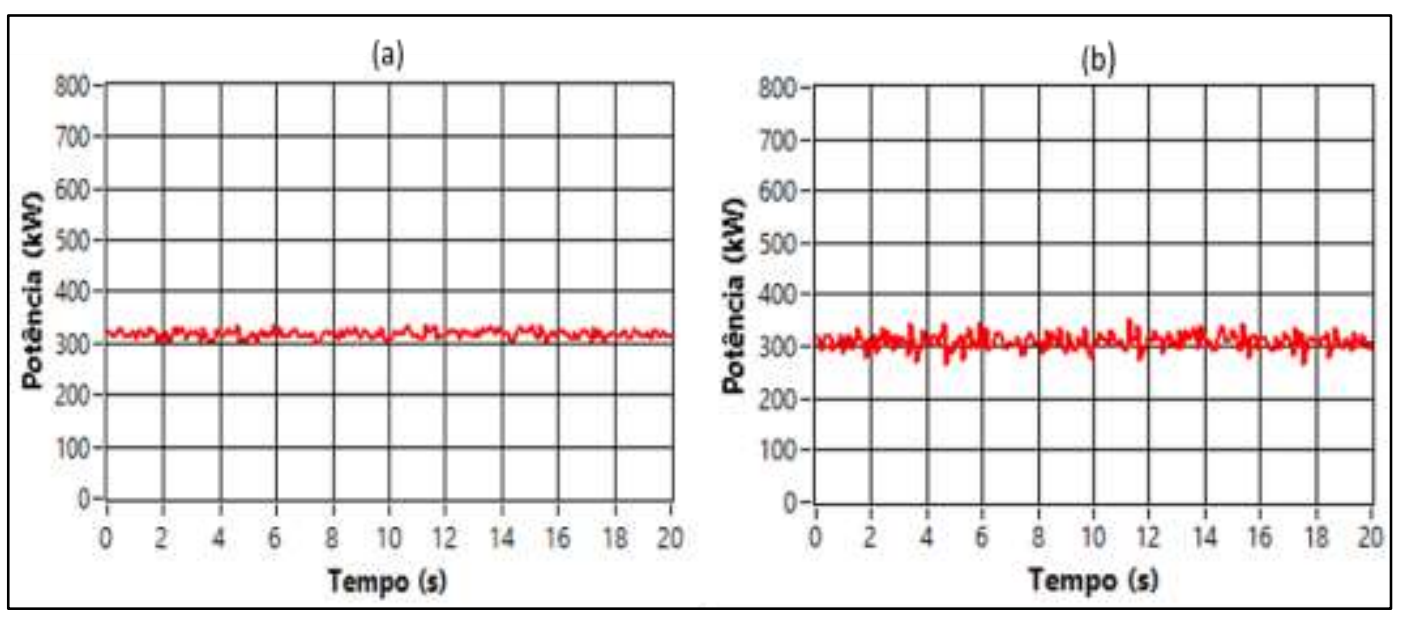

Fonte: Autores (2021).

É evidenciado pela Figura 8-a que a potência mecânica estimada também reflete uma alternância correspondente ao ruído, assumumindo amplitudes na faixa de $300 \mathrm{~kW}$. Para o cálculo em questão desconsidera-se as perdas mecânicas do sistema ou efeitos adversos.

Para a medição de potência do arranjo laboratorial, o método adotado é através da medição da corrente e tensão na armadura do motor CC, relatado na metodologia. Onde sabendo a resistência da armadura, define-se a tensão induzida que permitirá o cálculo da potência mecânica convertida na máquina em questão.

Nota-se que a medição de potência no sistema (Figura 8-b) apresenta uma curva característica semelhante a potência teórica calculada, também na ordem de $300 \mathrm{~kW}$. Todavia, apresenta uma maior oscilação devido a possíveis ruídos presentes no sistema de aquisição de dados. Outra causa passível desta maior dispersão, é o fato de se tratar de máquinas didáticas, que são construídas com critérios construtivos inferiores as máquinas de alto desempenho. Em súmula, pode-se afirmar que os resultados aqui demonstrados condizem com o esperado e respeitam os critérios da turbina em análise, que em uma escala real também traria medições diferentes da potência ideal teórica.

\subsubsection{Resultados do Caso 2}

A simulação deste caso tem propósito de analisar os casos de turbulências enfrentados pela geração eólica. Portanto, o vento constituí de uma componente rajada e uma componente rampa com amplitudes máximas de $2 \mathrm{~m} / \mathrm{s}$ com um vento base de $9,5 \mathrm{~m} / \mathrm{s}$, desta forma atingiria um valor de pico de $11,5 \mathrm{~m} / \mathrm{s}$, próximo a região nominal da turbina.

A rotação mecânica do conjunto de máquinas didáticas no caso em análise é mostrada na Figura 9. 
Figura 9: Rotação do sistema laboratorial - Caso 2.

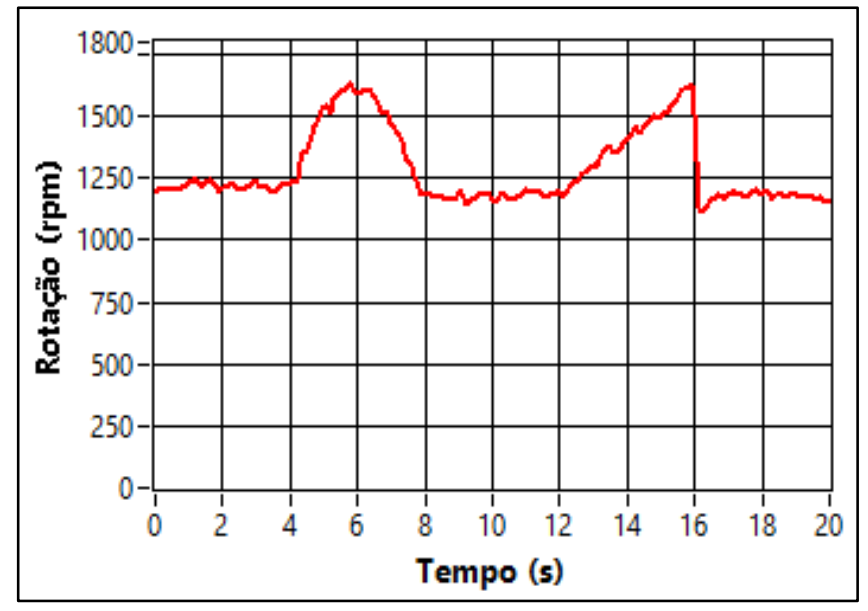

Fonte: Autores (2021).

É evidenciado na Figura 16 uma variação da rotação perante as turbulências incidentes, apresentando perfil semelhante à frente de onda enfrentada, partindo de valores próximos de 1200 rpm até em torno de 1600 rpm. Considerando para a escala da turbina em estudo, a sensibilidade de rotação causaria mudanças consideráveis em sua operação conforme as turbulências vivenciadas pelo sistema eólico, podendo afetar seu sistema mecânico.

O gráfico representativo da potência teórica e extraída neste caso segue na Figura 10.

Figura 10: (a) Potência mecânica teórica; (b) Potência mecânica extraída pela turbina.

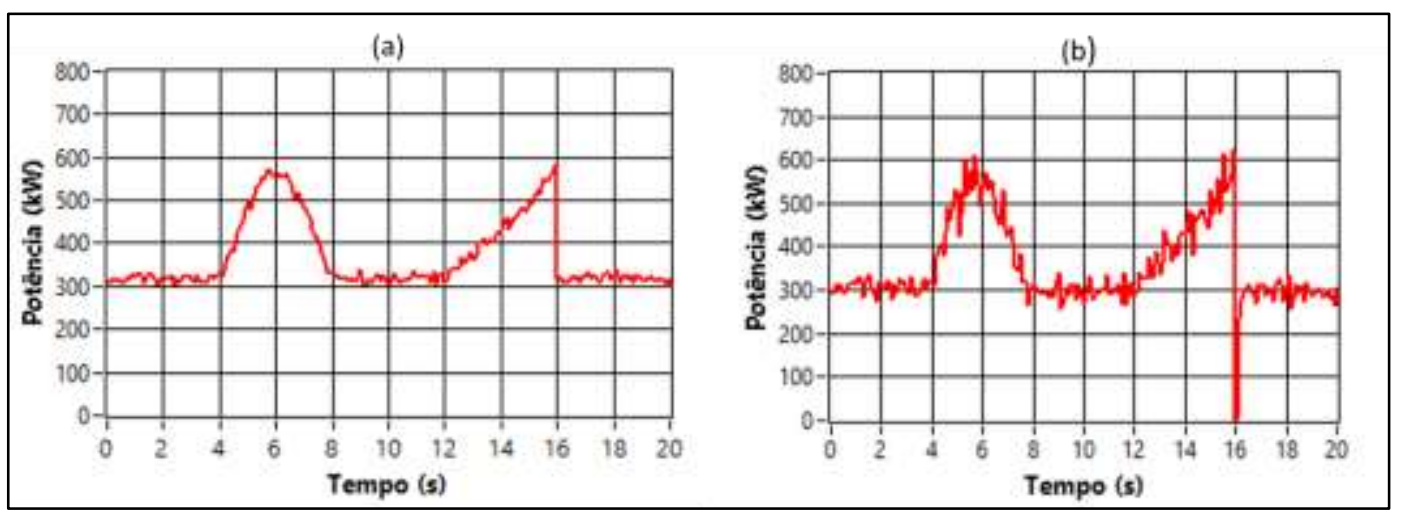

Fonte: Autores (2021).

Bem como o impacto da turbulência na rotação do sistema, ocorre uma alteração na potência mecânica teórica na qual o sistema estaria extraindo (Figura 10-a). Durante os períodos estacionários a potência se encontra próxima a $300 \mathrm{~kW}$, mas com uma variação na amplitude do vento de $2 \mathrm{~m} / \mathrm{s}$, os valores de potência chegaram próximos a $600 \mathrm{~kW}$. Isto acontece devido a potência presente no vento ser influenciada diretamente pelo cubo de sua velocidade, consoante ao relatado no estudo.

A potência extraída pela turbina representada na Figura 10-b, mantém as propriedades citadas no caso 1, apresentando uma ordem de potência semelhante ao potencial teórico, porém com maiores flutuações destes valores. Destaca-se uma maior atenção ao tempo de 16 segundos. No instante de tempo do final da rampa, uma queda brusca da potência mecânica acontece chegando até um valor nulo. Entretanto, este valor apresentado não condiz com a potência mecânica real do sistema.

Para explicar este fenômeno transitório, relembra-se o método de medição da potência mecânica adotada, sendo através da corrente e da tensão induzida no motor CC. Ao analisarmos o final da rampa o motor se encontra em aceleração e tende a continuar a inércia do movimento, porém ao reduzir a tensão de alimentação abruptamente para retornar ao valor de potência 
base anterior, ocasiona um efeito momentâneo onde a força contraeletromotriz supera a força eletromotriz, e anula a corrente na armadura por possuir polarização oposta ao sentido que a gerou. Causando assim uma "falsa medição" de potência mecânica que assumiria valor zero. Logo após a frenagem da máquina diminui-se a força contraeletromotriz e novamente o sistema retoma a potência mecânica antes da rampa, tudo isso ocorre em curto tempo de duração.

O citado sobre o efeito das forças resultantes na corrente de armadura do motor CC é ilustrado na Figura 11, com a unidade de medida em ampere.

Figura 11: Corrente na armadura do motor CC - Caso 2.

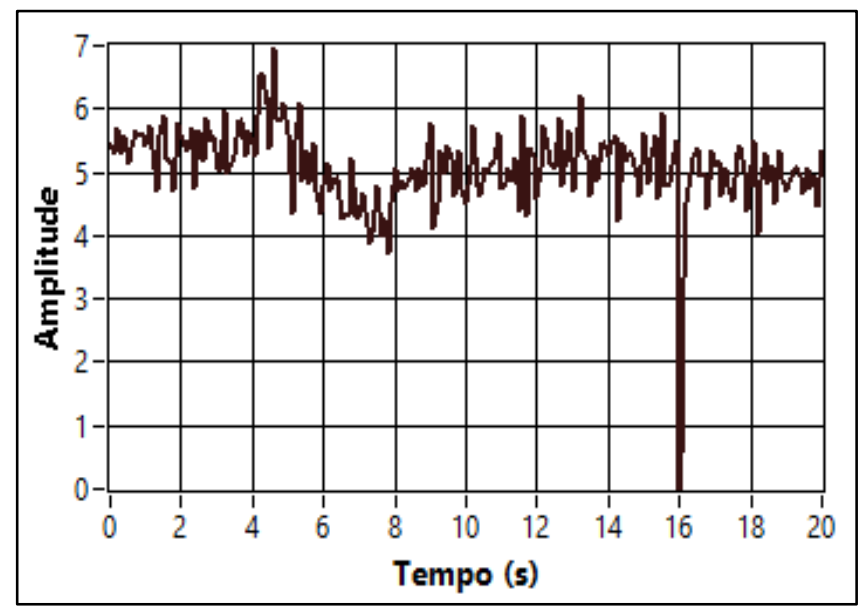

Fonte: Autores (2021).

Conforme explicado, é evidenciado por este gráfico o transitório de tempo em que a corrente na armadura tende a 0 A, e em uma fração de segundos retorna ao seu regime operacional quando o motor termina sua redução de velocidade, explicando o fato exposto na potência mecânica.

Para este caso, foi analisado também o impacto dessas turbulências nas ondas de tensão do sistema laboratorial. A Figura 12 retrata o perfil das tensões (em volts) medidas na armadura do motor CC no gráfico superior azul, e a tensão de linha eficaz (RMS) no gerador no gráfico inferior vermelho.

Figura 12: Tensões do sistema laboratorial - Caso 2.

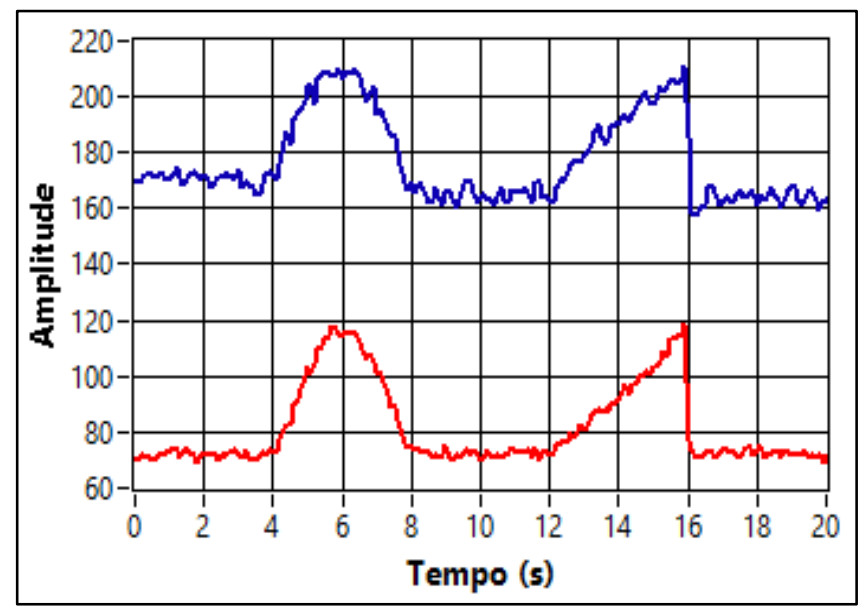

Fonte: Autores (2021). 
Nota-se que as tensões apresentadas nas máquinas sofrem influência diretamente da rotação do sistema, assim como as flutuações causadas pelo ruído presente no fluido, refletem em flutuação de tensões no gerador. Apesar da medição no gerador ser apenas referida a tensão de uma fase, dado que o sistema apresenta uma carga trifásica equilibrada, os valores de tensões apresentados nas outras duas fases corresponderiam ao mesmo módulo, apresentando uma defasagem entre si.

\subsubsection{Resultados do Caso 3}

O último caso simulado tem o propósito de verificar o sistema de controle desenvolvido, buscando apresentar os valores teóricos que o sistema real da turbina deve fornecer. Neste caso, o vento em análise apresenta amplitudes na rajada e na rampa de até $12,5 \mathrm{~m} / \mathrm{s}$, excedendo os valores nominais rotacionais, mecânicos e elétricos no qual o aerogerador foi projetado para operar.

O esboço da potência mecânica teórica localiza-se na Figura 13, onde semelhante ao caso 2, a potência sofre alterações com as situações adversas presentes na fonte primária de energia.

Figura 13: Potência mecânica teórica - Caso 3.

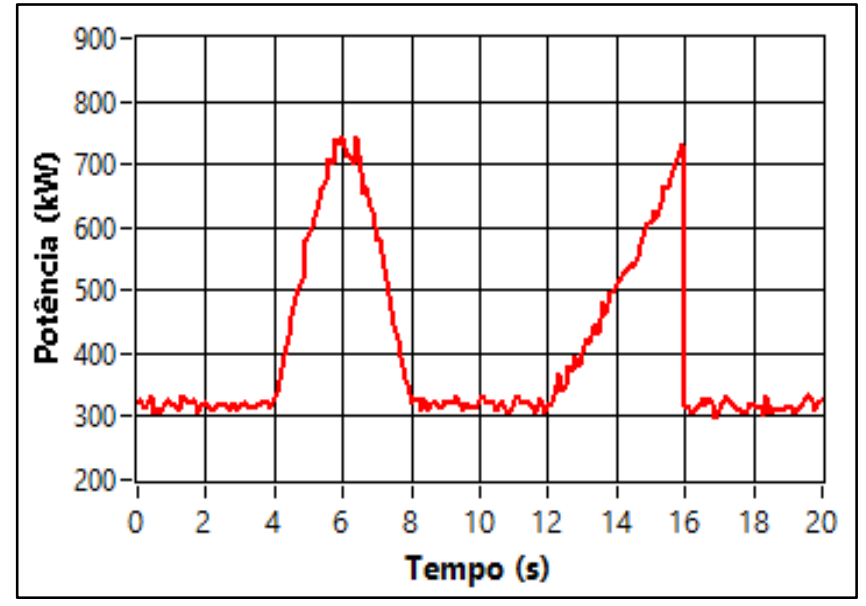

Fonte: Autores (2021).

O gráfico de potência apresentado informa valores de potência que ultrapassam até $700 \mathrm{~kW}$, tendo potencial de originar um esforço mecânico maior que o projeto da turbina em análise. Dado esta situação, deve-se operar o controle pitch da turbina, para que reduza a potência mecânica extraída. Posto isto, o gráfico de atuação das pás da turbina é ilustrado na Figura 14, onde nos momentos em que o vento ultrapasse os $12 \mathrm{~m} / \mathrm{s}$, ocorre a determinação do ângulo de passo teórico necessário para a proteção do sistema. 
Figura 14: Atuação do controle Pitch - Caso 3.

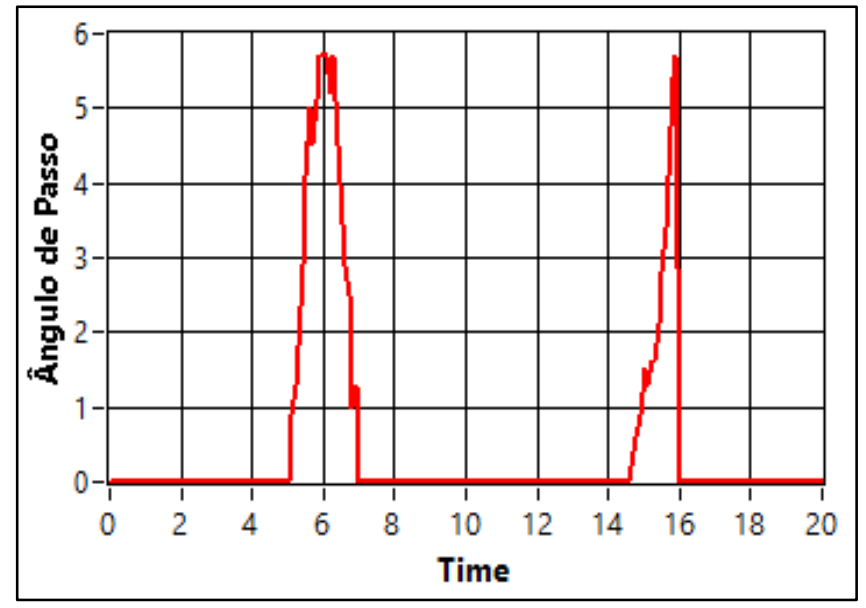

Fonte: Autores (2021).

Para as características aerodinâmicas apresentadas, a ultrapassagem de $0,5 \mathrm{~m} / \mathrm{s}$ na velocidade nominal de vento projetada implica na alteração dos ângulos de passo das pás em valores próximos a 2,5 graus, reduzindo sua área de contato com o vento e controlando por fim o coeficiente de potência, que reduz de seu valor nominal 0,4375 para valores em torno de 0,38.

Enfatiza-se que este controle requer um tempo de atuação, já que os mecanismos de rotação das pás devem movimentar gradualmente até o ponto desejado, portanto o tempo de atuação em escala real seria um pouco maior que o apresentado. Através da atuação pitch, o sistema de controle manterá a turbina em sua rotação nominal, evitando as possíveis falhas mecânicas que poderiam ser ocasionadas ao longo do tempo.

Deste modo, é indicado no gráfico presente na Figura 15, a velocidade mecânica do conjunto de máquinas, onde temse uma aceleração conforme vento incidente até seu valor nominal de $12 \mathrm{~m} / \mathrm{s}$ onde é atuado o controle.

Figura 15: Rotação do sistema laboratorial - Caso 3.

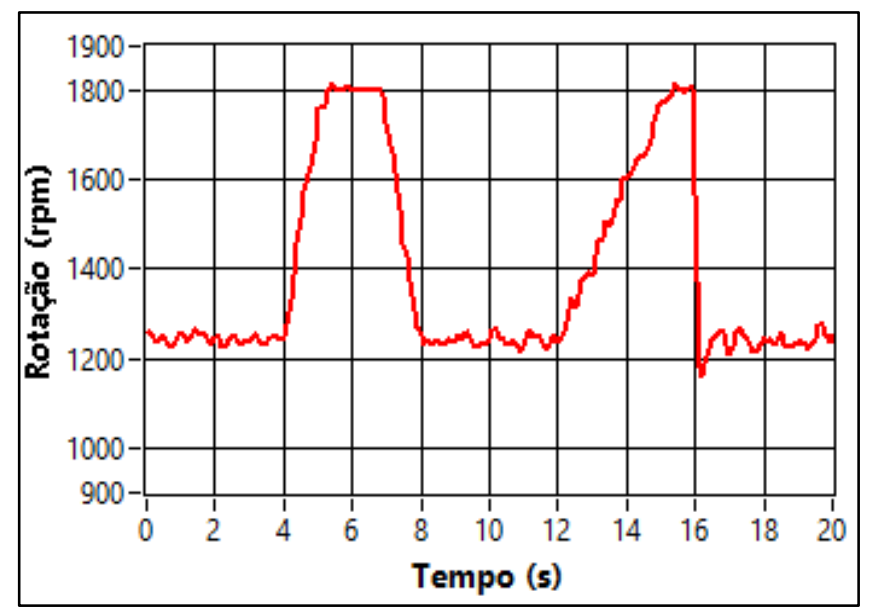

Fonte: Autores (2021).

Como dimensionado anteriormente, para rotação de $1800 \mathrm{rpm}$ a escala laboratorial representaria a rotação nominal da turbina em 33,6 rpm assumindo os valores nominais de potência mecânica e da tensão no gerador. Graças ao controle efetuado, nota-se na Figura 15 que as máquinas não ultrapassaram 1800 rpm, e da mesma forma, não foi excedido a tensão nominal de $220 \mathrm{~V}$ do gerador mantendo sua operação estável e evitando possíveis danos aos seus enrolamentos. 


\section{Considerações Finais}

A metodologia proposta para a reprodução de aerogeradores através do controle computacional aplicado em máquinas laboratoriais apresentou desempenho condizente com o que se propunha. O software desenvolvido permitiu realizar todo o controle, modelagem e monitoramento em tempo real do sistema simulado, com uma interface final intuitiva e interativa.

Verificou-se que o método adotado para aquisição do sinal de potência mecânica, baseado na medição da potência convertida pelo torque eletromagnético, pode vir a apresentar efeitos transitórios não constatados com a real potência no eixo no motor. Pode-se supor ainda, que as medições podem ter sido influenciadas pelos ruídos presentes nos sinais adquiridos, ou a um comportamento não linear dos sensores.

O modelo de representação do vento permitiu uma simulação fidedigna ao comportamento aleatório do fluido, tal qual as eventualidades de turbulências que são constatadas, propiciando deste modo, uma análise dos efeitos reais da geração de energia elétrica pelos sistemas eólicos.

O arranjo laboratorial proporcionou a análise dos efeitos mecânicos no qual as máquinas são submetidas frente a variação da potência mecânica, resultando em grandes esforços em momentos de turbulências, ressaltando a necessidade de um sistema de controle preciso e efetivo que proteja o aerogerador de todas as adversidades. Verificou-se também que a tensão de saída no gerador sofre com as flutuações de rotação do sistema e pode vir a alterar a qualidade da energia entregue as cargas consumidoras, necessitando de um sistema final de retificação e inversão para melhor desempenho elétrico.

Por fim, visto as constatações e discussões presentes durante todo o projeto, o modelo laboratorial deve seguir com futuras pesquisas e implementações até a consolidação do sistema. Sendo sugerido como trabalhos futuros:

- Estudo dos possíveis ruídos presentes no sistema de aquisição para projeção de um condicionamento de sinais que elimine as interferências e garanta maior precisão e confiabilidade nas medições;

- Implementar um processo de retificação e inversão na saída do gerador síncrono, permitindo controle do nível de tensão e frequência, possibilitando uma análise de integração do sistema em rede elétrica;

- Utilizar um torquímetro para leitura da potência mecânica através do torque presente no eixo, podendo realizar um sistema de controle em malha fechada;

- Aplicar um estudo de qualidade de energia, que permita mensurar e quantificar a influência dos efeitos encontrados na geração nos níveis de distorção aceitáveis.

\section{Referências}

Alvarenga, E. B. de. (2012). Uma proposta laboratorial para estudos de desempenho de unidades eólicas no contexto da qualidade de energia (Dissertação de mestrado). Universidade Federal de Uberlândia, Uberlândia, MG, Brasil.

Bonelli, A. F. (2010). Modelagem e simulação de unidade é́lica para estudos de indicadores de qualidade da energia elétrica (Dissertação de mestrado). Universidade Federal de Uberlândia, Uberlândia, MG, Brasil.

Carvalho, B. C. (2006). Desenvolvimento de modelo computacional de sistemas eólicos utilizando geradores síncronos para estudos de desempenho no contexto da qualidade da energia elétrica (Tese de Doutrado). Universidade Federal de Uberlândia, Uberlândia, MG, Brasil.

Chapman, S. J. (2013). Fundamentos de máquinas elétricas (5a ed.). (Anatólio Laschuk, Trad.). AMGH.

Fadigas, E. A. F. A. (2011). Energia eólica. Manole.

Gao, L., \& Luo, Y. (2009). Simulation of Imitation of the Characteristics of Wind Turbine Based on DC Motor with Matlab. International Conference on Sustainable Power Generation and Supply, 1-5, 10.1109/SUPERGEN.2009.5348190.

Kalmikov, A. (2017). Wind power fundamentals. In T. M. Letcher (Org.), Wind energy engineering: A handbook for onshore and offshore wind turbines. 1723. Elsevier.

Karzov, Z., \& Milenov, V. (2015, Outubro). Wind turbine emulator with de motor. International Conference on Electrical Machines, Drives and Power Systems ELMA, Varna, Bulgaria, 14.

Lin, B., Xiaofeng, L., \& He, X. (2011). Measurement system for wind turbines noises assessment based on LabVIEW. Measurement: Journal of the International Measurement Confederation, 44(2), 445-453. 
Mendes, V. F. (2009) Avaliação do comportamento de um sistema de conversão de energia eólica utilizando gerador de indução duplamente excitado durante afundamentos de tensão equilibrados e desequilibrados (Dissertação de mestrado). Universidade Federal de Minas Gerais, Belo Horizonte, MG, Brasil.

Nascimento Junior, G. C. do. (2013). Máquinas elétricas: Teoria e ensaios (4a ed.). Érica.

Neto, A. S. (2005). Análise e controle de centrais eólicas a velocidade variável utilizando Atpdraw (Dissertação de mestrado). Universidade Federal de Pernambuco, Recife, PE, Brasil.

Parreiras, T. M., \& Silva, S. R. (2012, Maio). Distorções harmônicas geradas por um parque de turbinas eólicas. Simpósio Brasileiro de Sistemas Elétricos, Goiânia, GO, Brasil, 4.

Silva, J. R. C. da. (2014). Otimização da posição de aerogeradores em parque eólico (Dissertação de mestrado). Universidade de Brasília, Brasília, DF, Brasil.

Silva, K. F. da. (2006). Controle e integração de centrais eólicas à rede elétrica com geradores de indução duplamente alimentados (Tese de doutorado). Escola Politécnica da Universidade de São Paulo, 2006.

Slootweg, J. G., Polinder, H., \& Kling, W. L. (2003). Representing wind turbine electrical generating systems in fundamental frequency simulations. Ieee Transactions On Energy Conversion, 18(4), 516-524.

Travis, J., \& Kring, J. (2006) Labview for everyone: Graphical programming made easy and fun (3a ed.). Prentice Hall.

Umans, S. D. (2014). Máquinas elétricas de Fitzgerald e Kingsley (7a ed.). (Anatólio Laschuk, Trad.). AMGH.

Witherspone, I. Z. (2014). Comparison between dSPACE and NI systems based on real-time intelligent control of a teleoperated hydraulic servo system (Tese de doutorado). Lappeenranta University of Technology, Lappeenranta, Finlândia.

Xavier, G. L. (2012). Avaliação de desempenho da estratégia de representação laboratorial de turbinas eólicas utilizando motores de indução controlados (Dissertação de mestrado). Universidade Federal de Uberlândia, Uberlândia, MG, Brasil. 